\title{
Fen Bilgisi ve Biyoloji Öğretmenliği Öğrencilerinin Kimyasal Etkileşimler Hakkında Yaptığı Tanımların İncelenmesi *
}

\section{Investigation of Science and Biology Teaching Students' Definitions related to Chemical Interactions}

\section{Gamze DOLU**}

\author{
Handan ÜREK ${ }^{* * *}$
}

Received: 29 May 2018

Research Article

Accepted: 05 November 2018

\begin{abstract}
The aim of this study is to investigate the definitions of university students related to the interactions among chemical species. Also, the effect of Inquiry Based Learning on those definitions has been searched in the study context. The study group consisted of first year Science Teaching ( $\mathrm{f}=51$ ) and Biology Teaching ( $\mathrm{f}=21$ ) students studying in one of the governmental universities in the west part of Turkey. A qualitative approach was utilized in the study. The students were requested to make definitions of nine concepts related to chemical interactions (chemical bond, ionic bond, dipole-dipole inreactions, covalent bond, hydrogen bond, ion-dipole interactions, metallic bond, Van der Waals interactions and induced dipole interactions). Data were collected in the form of pre and post tests and analyzed under four categories such as full correct, partially correct, incorrect and no response. As a result, it was identified that the definitions provided by the participants mostly improved due to teaching. Besides, several definitions (Van der Waals interactions, induced dipole interactions, dipole-dipole interactions) obtained from Biology Teaching students stayed in a restricted level despite teaching process. The study highlighted several points that should be considered by the chemistry educators during teaching as well as representing students' conceptions related to chemical interactions. Based on the study findings, it is recommended to utilize technological support such as animations during teaching of abstract concepts which students find difficult to understand.
\end{abstract}

Keywords: chemical bonds, inquiry-based learning, definitions.

ÖZ: Bu çalışmanın amacı, üniversite öğrencilerinin kimyasal türler arası etkileşimler ile ilgili yaptıkları tanımların incelenmesidir. Ayrıca, çalışma kapsamında Sorgulamaya Dayalı Öğrenmenin bu tanımlar üzerindeki etkisi araştırılmıştır. Çalışma grubu, Türkiye'nin batısında bulunan bir devlet üniversitesinin eğitim fakültesinin birinci sınıfında öğrenim görmekte olan Fen Bilgisi Öğretmenliği (f=51) ve Biyoloji Öğretmenliği (f=21) programı öğrencilerinden oluşmaktadır. Çalışmada nitel bir yaklaşımdan yararlanılmıştır. Öğrencilerden çalışma kapsamında kimyasal etkileşimler ile ilgili dokuz kavramı (kimyasal bağ, iyonik bağ, dipol-dipol etkileşimleri, kovalent bağ, hidrojen bağı, iyon-dipol etkileşimleri, metalik bağ, Van der Waals bağları ve indüklenmiş dipol etkileşimleri) tanımlamaları istenmiştir. Veriler, ön test-son test şeklinde toplanmış olup tam doğru, kısmen doğru, yanlış ve cevapsız olmak üzere dört kategori altında analiz edilmiştir. Çalışma sonucunda öğrencilerin yaptıkları tanımların çok büyük oranda geliştiği tespit edilmiştir. Bunun yanında Biyoloji Öğretmenliği programından elde edilen bazı tanımların düzeyinin (Van der Waals bağları, indüklenmiş dipol etkileşimleri, dipol-dipol etkileşimleri) yapılan öğretime rağmen daha düşük olduğu belirlenmiştir. Çalışma sonuçları, kimya eğitimcilerine kimyasal türler arası etkileşimler konusuyla ilgili öğrenci kavramaları hakkında bilgi vererek bu kapsamda dikkat edilmesi gereken kavramları ortaya koymaktadır. Çalışma sonuçlarına dayanılarak öğrencilerin anlamakta zorlandığı soyut kavramların öğretiminde animasyon gibi teknoloji desteğinden faydalanılması önerilmektedir.

Anahtar kelimeler: kimyasal bağlar, sorgulamaya dayalı öğrenme, tanımlar.

\footnotetext{
* This study is the extended version of oral presentation held in Afyonkarahisar, UBEK 2018 (Internation Congress on Science and Education)

** Corresponding Author: Assoc. Prof. Dr., Balıkesir University, Balıkesir, Turkey, agamze@ balikesir.edu.tr

${ }^{* * *}$ Res. Assist. Dr., Balıkesir University, Balıkesir, Turkey, handanurek@balikesir.edu.tr
}

Citation Information:

Dolu G., \& Ürek, H. (2018). Fen bilgisi ve biyoloji öğretmenliği öğrencilerinin kimyasal etkileşimler hakkında yaptığı tanımların incelenmesi. Kuramsal Eğitimbilim Dergisi [Journal of Theoretical Educational Science], UBEK2018, 81-99. 


\section{Giriş}

Kavramlar, bilgi bütününü oluşturan yapı taşları şeklinde açıklanmaktadır (Küçük, Çepni, \& Tavşan, 2004). Fen öğretiminin temel amaçlarından birisi olan kavram öğretiminin bilimsel açıdan kabul edilebilir bir şekilde gerçekleşmesi için ilk olarak öğrencilerin kavramların neler olduğundan haberdar olmaları gerekir. Ancak kavramlar, ezber yoluyla ya da tanımla öğretilecek bilgi parçaları şeklinde düşünülmemelidir (Ayas, 2012, s. 155).

Okullarda gerçekleştirilen öğrenmeler, genel olarak bilişsel alanda yoğunlaşmaktadır (Senemoğlu, 2009, s. 404). Bilişsel alanın düzeyleri ise daha önce Bloom ve arkadaşları tarafindan altı basamak ile açıklanmıştır (Bloom, Engelhart, Furst, Hill, \& Krathwohl, 1956; akt: Krathwoh, 2002). Original Taxonomy olarak anılan bu taksonomide yer alan basamaklar; (i) Bilgi Basamağı (ii) Kavrama Basamağı (iii) Uygulama Basamağı (iv) Analiz Basamağı (v) Sentez Basamağı (vi) Değerlendirme Basamağ şeklindedir. Daha sonra, bu taksonomi gözden geçirilerek Bloom Taxonomy Revised şeklinde tekrar alanyazında yerini almıştır (Airasian ve diğerleri, 2001). Bloom'un gözden geçirilmiş taksonomisinde bahsedilen öğrenme basamakları ise (i) Hatırlama (ii) Anlama (iii) Uygulama (iv) Analiz etme (v) Değerlendirme (vi) Yaratma şeklindedir. Hem orijinal hem de gözden geçirilmiş Bloom Taksonomisinde dikkati çeken bir nokta, bilişsel alanın ilk olarak bilgi/hatırlama basamağı ile başlaması yani bilme üzerine kurulmuş olmasıdır. Bir başka deyiş ile bu basamağın, öğrencilerin öğrenmeleri için bir eşik oluşturduğu söylenebilir. Bir bilginin uygulanması, analiz edilmesi, değerlendirilmesi gibi üst düzey beceriler ancak o bilgi kazanıldıktan sonra gerçekleştirilebilir.

Bilme, bilişsel alanın her ne kadar en basit kısmını oluşturuyor gibi görünse de bu basamak öğrenme açısından oldukça önem taşımaktadır. Öğrencilerin eğitim sürecinde sıkıntı yaşadıkları durumlardan birisini, bildiklerini ifade etmenin oluşturduğu söylenebilir. Öğrencilerin bildiklerini iddia ettikleri kavramları ifade etmede ve çevresindekilere aktarmada sıkıntı yaşamaları oldukça düşündürücüdür. Bu durumun bir diğer yansıması ise sınavlarda ortaya çıkmaktadır. Öğrencilerin çoktan seçmeli test sorularına karşı sempati duydukları, açık uçlu sorulardan oluşan sınavlara karşı ise yüksek derecede endişe ile yaklaştıkları görülmektedir (Dolu \& Ürek, 2018). Üniversiteye gelen öğrencilerin üniversite sınavına çoktan seçmeli test soruları ile hazırlık yaptıkları ve bu tarz sorular ile belirlendikleri düşünüldügünnde, açık uçlu soruların cevaplanması onları zorlayan bir durum olarak karşımıza çıkmaktadır.

Ülkemizde yükseköğretim kurumlarının amaçlarından birisi de "Yükseköğretim kurumları olarak yüksek düzeyde bilimsel çalışma ve araştırma yapmak, bilgi ve teknoloji üretmek, bilim verilerini yaymak, ulusal alanda gelişme ve kalkınmaya destek olmak, yurt içi ve yurt dişı kurumlarla iş birliği yapmak suretiyle bilim dünyasının seçkin bir üyesi haline gelmek, evrensel ve çağdaş gelişmeye katkıda bulunmaktır." şeklinde ifade edilmektedir (YÖK, 1981). Bu amaç ancak bireylerin düşünme becerilerinin geliştirilmesi ile yerine getirilebilir. Eğitim fakültelerinde öğrenim görerek ileride öğretmen olarak görev yapacak kişiler açısından düşünüldüğünde ise durumun önemi tekrar ortaya çıkmaktadır. Bu tür becerilerin geliştirilmesi için alanyazında öğrenci merkezli öğrenme yaklaşımlarının ön plana çıktığı görülmektedir. $\mathrm{Bu}$ çerçevede, Sorgulamaya Dayalı Öğrenme üzerinde durulan bu yaklaşımlardan biridir. 


\section{Sorgulamaya Dayalı Öğrenme}

Sorgulamaya Dayalı Öğrenme, öğrencinin özgür bir ortamda çalışıp ihtiyaç duyduğu bilgileri sorguladığı bir öğrenme yaklaşımıdır (Bayram, 2015, s. 446). Öğrenme sürecinde öğrencilerin hem zihinsel hem de fiziksel olarak aktif bir şekilde yer

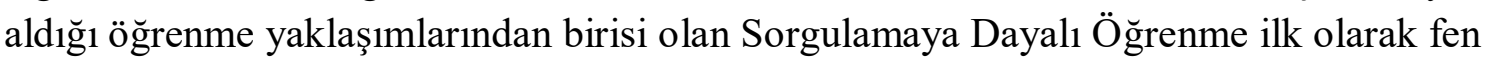
bilimleri öğretiminde kullanılmaya başlanılmıştır (Çelik, Şenocak, Bayrakçeken, Taşkesenligil, \& Doymuş, 2005). Sorgulamanın amac1; öğrencilerin çevrelerinde meydana geleni anlamaları, bilinmeyeni bulmaları ve doğaya anlam vermeleridir (Bostan Sarığlan \& Abacı, 2017).

Sorgulamaya Dayalı Öğrenmeyi temel alan araştırmaların ülkemizdeki alanyazında nispeten yeni olduğu söylenebilir. Bu kapsamda ortaokul seviyesindeki öğrenciler ile gerçekleştirilen bazı çalışmaların, madde (Şimşek \& Kabapınar, 2010); kuvvet ve hareket (Kaya \& Yılmaz, 2016); lamba parlaklığı (Bostan Sarı̆̆lan \& Abacı, 2017) gibi fen konularında öğrenci başarısına odaklandığı görülmektedir. Üniversite seviyesindeki öğrenciler ile bu yaklaşım çerçevesinde yürütülmüş çalışmaların ise bilimsel süreç becerileri ve laboratuvar algısına tutum (Duru, Demir, Önen, \& Benzer, 2011); sorgulamaya dayalı öğrenme becerileri algıları (Karamustafaoğlu \& Celep Havuz, 2016); öz-yeterlik ve sorgulamaya dayalı öğretime ilişkin inançlar (Kocagül, 2013); motivasyon (Sarı \& Bakır Güven, 2013) gibi akademik başarıdan farklı yönlere odaklandığ1 görülmektedir. Üniversite seviyesindeki öğrencilerin kavramsal anlamalarına odaklanan çalışmaların ise sınırlı olduğu dikkati çekmektedir (Kayacan \& Selvi, 2017).

Sorgulamaya Dayalı Öğrenmenin Dünyada yapılan araştırmalardaki yerine bakıldığında ise bu yaklaşımın Dünyadaki geçmişinin yerli araştırmalara göre daha eski olduğu dikkati çekmektedir (Edelson, Gordin, \& Pea, 1999; Magnussen, Ishida, \& Itano, 2000). Nitekim Spronken-Smith ve Walker (2010) bu yaklaşımın 1970'lerden beri okullarda uygulanmakta olduğunu belirtmektedir. Yapılan araştırmalarda, Sorgulamaya Dayalı Öğrenmenin ortaokul düzeyinden (Abdi, 2014; Wu \& Hsieh, 2006) üniversite düzeyine (Gormally, Brickman, Hallar, \& Armstrong, 2009; Levy \& Petrulis, 2012; Oliver, 2007) farklı sınıf seviyelerinde öğrenim görmekte olan öğrencilere uygulandığ1 görülmektedir. $\mathrm{Bu}$ çalışmalarda; Sorgulamaya Dayalı Öğrenmenin öğrencilerin öğrenme ihtiyacını ne derece karşıladığı (Oliver, 2007), bilimsel okuryazarlıklarına ve güvenlerine etkisi (Gormally, Brickman, Hallar, \& Armstrong, 2009) ve bu yaklaşımla ilgili görüşler (Levy \& Petrulis, 2012) ele alınmıştır. Üniversite düzeyindeki öğrenciler ile yapılan çalışmalar değerlendirildiğinde yerli çalışmalarda olduğu gibi bu çalışmaların da çoğunlukla kavramsal anlamalardan farklı noktalara odaklandıkları dikkati çekmektedir. Bu yaklaşım kullanılarak kavramsal anlamalar konusunda yapılan çalışmaların ise yetersiz olduğu görülmektedir.

Sorgulamaya Dayalı Öğrenme, üç farklı yaklaşımla gerçekleştirilebilmektedir. Bunlar; (i) Yapılandırılmış Sorgulama (ii) Rehberli Sorgulama ve (iii) Açık Sorgulama şeklinde olup şöyle açıklanmaktadır (Spronken-Smith \& Walker, 2010):

(i) Yapılandırılmış Sorgulama, öğretmenlerin öğrencilere bir durum ya da bir problem ile birlikte bunu sorgulamaları için bir taslak da verdikleri sorgulama türüdür. 
(ii) Rehberli Sorgulama, öğretmenlerin öğrencilerin sorgulamaya başlamalar1 için sorular sordukları ancak öğrencilerin bu sorulara cevaplar aramada kendi kendilerine yönlendikleri sorgulama türüdür.

(iii) Açık Sorgulama, öğrencilerin hem sorgulayacakları soruları kendilerinin oluşturduğu hem de sorgulama sürecine tam anlamıyla katıldıkları türdür.

Öğrencilerin bir durumu sorgulayabilmelerinde mevcut bilgileri ve mevcut bilgileri ile yeni karşılaştıkları durum arasında bağlantılar kurabilmeleri önem taşımaktadır. Nitekim fen öğreniminin de birikimli bir süreç olduğu ve bir konuyla ilgili öğrenilen her yeni bilginin sahip olunan bilgilerin üzerine eklendiği belirtilmektedir (Özmen, 2004). Fen eğitiminde kimyasal bağlar konusu ise öğrencilerin anlamada zorlandıkları bir konu olarak karşımıza çıkmaktadır. Kimyasal bağlar konusunun doğrudan gözlenemeyen kavramlar içermesi (elektron, bağ, etkileşim), günlük yaşamda doğrudan uygulamasının bulunmaması ve öğrencilerin bu konudaki kavramları mikroskobik düzeyden makroskobik düzeye dönüştürememeleri, bu konuyu öğrenciler açısından anlaşılması zor bir hale getirmektedir (Tan \& Treagust, 1999; Uzuntiryaki, 2003). Araştırmalar, gerek lise (Acar \& Tarhan, 2008; Öztürk Ürek \& Tarhan, 2005; Tan \& Treagust, 1999) gerekse üniversite öğrencilerinin (Luxford \& Lowery Bretz, 2013; Yılmaz \& Morgil, 2001) bu konuyla ilgili birçok kavram yanılgısı taşıdığını göstermektedir. Ayrıca öğrencilerin hangi öğrenim düzeyinde olursa olsun bu kapsamda basit zihin modelleri geliştirme eğiliminde oldukları tespit edilmiştir (Coll \& Taylor, 2002; Coll \& Treagust, 2003). Ancak kimyasal bağ konusunun anlaşılması; kimyasal denge, termodinamik, molekül yapısı ve kimyasal tepkimeler gibi çeşitli kimya konularının öğrenilmesine temel oluşturmaktadır (Özmen, 2004). Bu nedenlerle, yapılan çalışmada kimyasal bağlar konusuna kimyasal türler arası etkileşimler açısından yaklaşılmıştır.

\section{Araştırmanın Amacı}

$\mathrm{Bu}$ çalışmanın amacı, üniversite öğrencilerinin kimyasal etkileşimlerle ilgili kavramlara yönelik yaptıkları tanımların incelenmesi ve gerçekleştirilen Sorgulamaya Dayalı Öğrenmenin, öğrencilerin bu kavramları tanımlamaları üzerindeki etkisinin ortaya çıkarılmasıdır.

\section{Araştırmanın Önemi}

Yapılan çalışmada bilme basamağının, analiz, sentez gibi daha üst düzey beceriler için öğrenme sürecinde bir eşik oluşturduğu kabul edilerek bu durum üniversite öğrencileri açısından ele alınmıştır. Ayrıca, bu durum; araştırmada odaklanılan öğrenci grubunun Eğitim Fakültesi gibi öğretmen yetiştiren bir fakültenin öğrencilerinden oluşmaları ve yakın gelecekte öğretmen olarak görev yapacak olmaları açısından da oldukça önem arz etmektedir. Bunun yanında, bu basamağın Genel Kimya Dersi konularından birisi olan kimyasal türler arası etkileşimlerle ilgili kavramlar çerçevesinde ele alınması, bu becerinin ne derece aktarıldığını göstermesi açısından önemlidir. 


\section{Yöntem}

\section{Araştırma Modeli}

Yapılan araştırma, nitel bir yaklaşım ile gerçekleştirilmiş olup bir durum çalışması modelindedir. Durum çalışması, bir ya da birden fazla olayın, ortamın, programın, sosyal grubun, topluluğun, bireylerin ya da birbirine bağlı sistemlerin ayrıntılı olarak incelendiği yöntem şeklinde tanımlanmaktadır (McMillan, 2004, s. 271).

\section{Çalışma Grubu}

Çalışma grubunu, Türkiye'nin batısında bulunan bir devlet üniversitesinin eğitim fakültesinin birinci sınıfında öğrenim görmekte olan Fen Bilgisi Öğretmenliği Programı ( $f=51)$ ve Biyoloji Öğretmenliği Programı öğrencileri ( $f=21$ ) oluşturmaktadır. Örneklem seçiminde, araştırmacılara yakın ve erişilmesi kolay bir durum seçilerek araştırmaya hız ve pratiklik kazandırması açısından kolay ulaşılabilir örnekleme yaklaşımından yararlanılmıştır (Yıldırım \& Şimşek, 2008, s. 113).

\section{Veri Toplama Aracı}

Çalışmanın verileri, araştırmacılar tarafından geliştirilmiş dokuz adet açık uçlu sorudan oluşan Kimyasal Etkileşimleri Kavrama Testi yardımıyla toplanmıştır. Bu test kapsamında ele alınan kavramlar şöyle sıralanabilir:

- Kimyasal bağ

- İyonik băg

- Dipol - dipol etkileşimleri

- Kovalent bağ

- Hidrojen bağ 1

- İyon - dipol etkileşimleri

- Metalik băg

- Van der Waals bağları

- İndüklenmiş dipol etkileşimleri (London kuvvetleri)

Veri toplama aracında öğrencilerden, bu kavramları kendi cümleleri ile tanımlamaları istenmiştir. Böylece çalışmadan nitel veriler elde edilmiştir.

\section{Araştırma Süreci}

Yapılan çalışma; veri toplama aracının ön test uygulamasını, öğretim sürecini ve son test uygulamasını içermektedir. Ön test ve son test süreci, veri toplama aracının öğrencilere birer ders saati içerisinde araştırmacıların gözetiminde uygulanmasını kapsamaktadır. Öğretim süreci ise Kimyasal Etkileşimler konusunun 2 ders saati (90 dakika) boyunca Rehberli Sorgulama Yöntemi ile öğretimini kapsamaktadır. Bu süreçte izlenen öğrenme basamakları şöyledir:

- Öncelikle tanımlanması gereken kavramların isimleri, öğretmen tarafından tahtaya yazild1.

- Her bir kavramın tanımlanması için öğrencilerin kendi aralarında tartışma yapmaları sağlandı.

- Tartışmalar sonucunda öğrencilerden, tanımlar ile ilgili açıklama yapmaları istendi. 
- $\mathrm{Bu}$ açıklamalar sonucunda öğrencilerin birbirlerinin fikirlerinin doğruluğunu, eksikliğini veya yanlışlığını görmeleri sağlandı.

- Öğrenciler, yaptıkları sorgulamalar sonucunda doğru tanımlamalara ulaştılar.

- Öğretmen, öğrencilerin ulaştığı doğru tanımlamaları tekrarlayarak öğretim sürecini tamamlad1.

Çalışma boyunca öğretim süreci her iki programda da Sorgulama Temelli Öğrenme basamakları uygulanarak aynı araştırmacı tarafından gerçekleştirilmiştir.

\section{Veri Analizi}

Öğrencilerden elde edilen nitel veriler, içerik analizine tabi tutularak çalışmanın her iki araştırmacısı tarafından ayrı ayrı incelenmiştir. İçerik analizi, ele alınan metinlerdeki bazı kelimelerin, belirli kurallara dayalı olarak oluşturulan kodlamalar yardımıyla daha küçük içerikteki kategoriler ile özetlendiği tekniktir (Büyüköztürk, Kılıç Çakmak, Akgün, Karadeniz, \& Demirel, 2010, s. 269). Yapılan analizler sonucunda, öğrencilerden elde edilen cevapların Tam Doğru, Kısmen Doğru, Yanlış ve Cevapsız olmak üzere dört kategori altında toplandığı belirlenmiştir. Araştırmada ele alınan kavramlar için beklenen bilimsel tanımlar Tablo 1'de yer almaktadır (Chang, 2000; Dolu, 2017; Petrucci, Herring, Madura, \& Bissonnette, 2012).

\section{Tablo 1}

Araştırılan Kavramların Bilimsel Tanımları

\begin{tabular}{|c|c|}
\hline Kavram & Bilimsel Tanım \\
\hline Kimyasal Bağ & İki atomu bir arada tutan kuvvetlere denir. \\
\hline İyonik Bağ & $\begin{array}{l}\text { Metaller elektron vererek (+) ile yüklenir. Böylece metal katyonları } \\
\text { oluşur. Ametaller metalin verdiği elektronları alarak (-) ile yüklenir. } \\
\text { Böylece ametal anyonları oluşur. Katyonlar ve anyonlar arasında } \\
\text { elektrostatik bir çekim meydana gelir. Bu çekim sonucunda oluşan bağdır. }\end{array}$ \\
\hline Dipol-Dipol Etkileşimleri & $\begin{array}{l}\text { Polar moleküllerde } \delta \text { - ve } \delta+\text { yüklerin birbirini çekmesi sırasında oluşan } \\
\text { çekim sonucu meydana gelen zayıf etkileşimlerdir. }\end{array}$ \\
\hline Hidrojen Bağ1 & $\begin{array}{l}\text { Hidrojenin elektronegatifliği büyük olan } \mathrm{F}, \mathrm{O}, \mathrm{N} \text { atomlarıyla oluşturduğu } \\
\text { bileşiklerde, molekülleri bir arada tutan kuvvete denir. }\end{array}$ \\
\hline Kovalent Bağ & $\begin{array}{l}\text { Ametallerin arasında oluşan ve elektronların ortak kullanılmasına dayanan } \\
\text { bağa denir. }\end{array}$ \\
\hline İyon-Dipol Etkileşimleri & Bir iyon ile bir polar molekül arasında görülen zayıf etkileşimlere denir. \\
\hline Metalik Bağ & $\begin{array}{l}\text { Metal kristalindeki metal katyonları ile delokalize (metallerin boş değerlik } \\
\text { orbitallerine geçiş yapabilen) elektronlar arasındaki çekime denir. }\end{array}$ \\
\hline Van der Waals Bağları & $\begin{array}{l}\text { Apolar moleküllerde, soygazlarda ve yoğun fazlarda sadece kütlelerinden } \\
\text { kaynaklanan bir çekim kuvveti oluşur. Bu kuvvete denir. }\end{array}$ \\
\hline $\begin{array}{l}\text { İndüklenmiş Dipol } \\
\text { Etkileşimleri }\end{array}$ & $\begin{array}{l}\text { Apolar moleküller arasında görülür. Belli bir anda elektronların bir } \\
\text { atomun ya da molekülün bir bölgesine yığılması olasılığı vardır. Bu } \\
\text { durumda molekül anlık olarak polarlaşır ve anlık dipoller oluşur. Bu } \\
\text { durumdan komşu tanecikler etkilenir ve geçici dipoller oluşturur. Bu bir } \\
\text { indüklenme olayıdır. Buna indüklenmiş dipol etkileşimleri veya London } \\
\text { kuvvetleri de denir. }\end{array}$ \\
\hline
\end{tabular}


Veri analizi sonuçları, betimsel istatistik yardımıyla farklı iki programda öğrenim gören öğrenciler arasında frekans ve yüzde dağılımları açısından ön test- son test için karşılaştırılmıştır.

Veri analizinin güvenirliği ise, her bir kavram için yapılan tanımlara yönelik iki araştırmacı arasındaki görüş birliklerinden ve görüş ayrılıklarından yola çıkılarak yapılan hesaplama sonucunda \%94 olarak hesaplanmıştır (Miles \& Huberman, 1994, s. 64). $\mathrm{Bu}$ sonuç, \%70'in üzerinde olduğundan veri analizinin güvenilir olduğunu göstermektedir (Yıldırım \& Şimşek, 2008, s. 233).

\section{Bulgular}

Araştırmadan elde edilen bulgular, her bir kavram için frekans ve yüzde dağılımı halinde öğrenim görülen program açısından karşılaştırılarak sunulmuştur.

\section{Kimyasal Bağ Kavramının Tanımlarının Analizinden Elde Edilen Bulgular}

Çalışmaya katılan öğrencilerden, kimyasal bağ kavramının tanımına dair elde edilen bulgular Tablo 2'de sunulmaktadır.

Tablo 2

Kimyasal Băg Kavramının Tanımları

\begin{tabular}{lcccc}
\hline & \multicolumn{2}{c}{ Fen Bilgisi Öğretmenliği } & \multicolumn{2}{c}{ Biyoloji Öğretmenliği } \\
\hline Kategoriler & Ön Test & Son Test & Ön Test & Son Test \\
\hline Tam Doğru & $17(\% 33.3)$ & $38(\% 74.5)$ & $5(\% 23.8)$ & $9(\% 42.9)$ \\
Kısmen Doğru & $14(\% 27.5)$ & $7(\% 13.7)$ & $3(\% 14.3)$ & $6(\% 28.6)$ \\
Yanlış & $17(\% 33.3)$ & $4(\% 7.8)$ & $4(\% 19.0)$ & $2(\% 9.5)$ \\
Cevapsız & $3(\% 5.9)$ & $2(\% 3.9)$ & $9(\% 42.9)$ & $4(\% 19.0)$ \\
\hline
\end{tabular}

Tablo 2'ye göre her iki programda öğrenim görmekte olan öğrencilerin kimyasal bağ kavramıyla ilgili tanımlarının öğretim sonunda, öncesine göre geliştiği dikkati çekmektedir.

\section{İyonik Bağ Kavramının Tanımlarının Analizinden Elde Edilen Bulgular}

Tablo 3

Iyonik Bă̆ Kavramının Tanımları

\begin{tabular}{lcccc}
\hline & \multicolumn{2}{c}{ Fen Bilgisi Öğretmenliği } & \multicolumn{2}{c}{ Biyoloji Öğretmenliği } \\
\hline Kategoriler & $\ddot{n} n$ Test & Son Test & Ön Test & Son Test \\
\hline Tam Doğru & $11(\% 21.6)$ & $31(\% 60.8)$ & $3(\% 14.3)$ & $8(\% 38.1)$ \\
Kısmen Doğru & $33(\% 64.7)$ & $17(\% 33.3)$ & $15(\% 71.4)$ & $12(\% 57.1)$ \\
Yanlış & $7(\% 13.7)$ & $3(\% 5.9)$ & $3(\% 14.3)$ & $1(\% 4.8)$ \\
Cevapsız & - & - & - & - \\
\hline
\end{tabular}


Katılımcılardan, iyonik bağ kavramının tanımına dair elde edilen bulgular Tablo 3'te yer almaktadir.

Tablo 3 incelendiğinde bir önceki sorudan elde edilen bulgulara benzer bir şekilde iyonik bağ kavramının tanımlarında da her iki programda öğrenim görmekte olan öğrencileri için öğretim sonunda, öncesine göre gelişmeler olduğu tespit edilmiştir. İyonik bağ kavramında hem ön testte hem de son testte her iki program öğrencileri tarafindan da cevapsız soru bırakılmaması, bir diğer dikkat çekici bulgudur.

\section{Edilen Bulgular}

Dipol-Dipol Etkileşimleri Kavramının Tanımlarının Analizinden Elde

Dipol-Dipol Etkileşimleri Kavramının tanımı kapsamında araştırmaya katılan öğrencilerden elde edilen bulguların sunumu Tablo 4 'te gösterilmektedir.

Tablo 4

Dipol-Dipol Etkileşimleri Kavramının Tanımları

\begin{tabular}{lcccc}
\hline & \multicolumn{2}{c}{ Fen Bilgisi Öğretmenliği } & \multicolumn{2}{c}{ Biyoloji Öğretmenliği } \\
\hline Kategoriler & Ön Test & Son Test & Ön Test & Son Test \\
\hline Tam Doğru & $5(\% 9.8)$ & $19(\% 37.3)$ & $1(\% 4.8)$ & $2(\% 9.5)$ \\
Kismen Doğru & $23(\% 45.1)$ & $24(\% 47.1)$ & $12(\% 57.1)$ & $16(\% 76.2)$ \\
Yanlış & $13(\% 25.5)$ & $6(\% 11.8)$ & $3(\% 14.3)$ & $2(\% 9.5)$ \\
Cevapsiz & $10(\% 19.6)$ & $2(\% 3.9)$ & $5(\% 23.8)$ & $1(\% 4.8)$ \\
\hline
\end{tabular}

Tablo 4'e göre her iki programda öğrenim görmekte olan öğrencilerin dipoldipol etkileşimleri kavramıyla ilgili tanımlarının öğretim sonunda, öncesine göre geliştiği dikkati çekmektedir. Ancak bu gelişmenin Biyoloji Öğretmenliği programında öğrenim görmekte olan öğrenciler için daha düşük bir oranda gerçekleştiği bulunmuştur.

Hidrojen Bağı Kavramının Tanımlarının Analizinden Elde Edilen Bulgular

Hidrojen Bağı Kavramının tanımıyla ilgili katılımcılardan elde edilen bulgular Tablo 5 'te yer almaktadır.

Tablo 5

Hidrojen Băğ Kavramının Tanımları

\begin{tabular}{lcccc}
\hline & \multicolumn{2}{c}{ Fen Bilgisi Öğretmenliği } & \multicolumn{2}{c}{ Biyoloji Öğretmenliği } \\
\hline Kategoriler & $\ddot{O} n$ Test & Son Test & Ön Test & Son Test \\
\hline Tam Doğru & $4(\% 7.8)$ & $18(\% 35.3)$ & $1(\% 4.8)$ & $6(\% 28.6)$ \\
Kismen Doğru & $3(\% 5.9)$ & - & $3(\% 14.3)$ & $1(\% 4.8)$ \\
Yanlış & $42(\% 82.4)$ & $33(\% 64.7)$ & $14(\% 66.7)$ & $13(\% 61.9)$ \\
Cevapsız & $2(\% 3.9)$ & - & $3(\% 14.3)$ & $1(\% 4.8)$ \\
\hline
\end{tabular}


Tablo 5 incelendiğinde önceki sorularda olduğu gibi öğrencilerin yaptığ1 tanımların öğretim sonucunda, öncesine göre gelişmeler gösterdiği belirlenmiştir. Ancak bu oranın Biyoloji Öğretmenliği öğrencileri için daha düşük bir seviyede kaldığı görülmektedir.

\section{Kovalent Bağ Kavramının Tanımlarının Analizinden Elde Edilen Bulgular}

Çalışmaya katılan öğrencilerden, kovalent bağ kavramının tanımına dair elde edilen bulgular Tablo 6'da sunulmaktadır.

Tablo 6

Kovalent Bă̆ Kavramının Tanımları

\begin{tabular}{lcccc}
\hline & \multicolumn{2}{c}{ Fen Bilgisi Öğretmenliği } & \multicolumn{2}{c}{ Biyoloji Öğretmenliği } \\
\hline Kategoriler & On Test & Son Test & Ön Test & Son Test \\
\hline Tam Doğru & $24(\% 47.1)$ & $43(\% 84.3)$ & $15(\% 71.4)$ & $15(\% 71.4)$ \\
Kismen Doğru & $16(\% 31.4)$ & $6(\% 11.8)$ & $5(\% 23.8)$ & $5(\% 23.8)$ \\
Yanlış & $11(\% 21.6)$ & $2(\% 3.9)$ & $1(\% 4.8)$ & $1(\% 4.8)$ \\
Cevapsiz & - & - & - & - \\
\hline
\end{tabular}

Tablo 6'ya göre Fen Bilgisi Öğretmenliği Programı öğrencilerinin kovalent bağ kavramı ile ilgili yaptığı tanımların öğretim sonunda, öğretim öncesine göre geliştiği görülmektedir. Buna karşılık Biyoloji Öğretmenliği Programı öğrencilerinin tanımlarının ise öğretim sonunda öncesine göre değişiklik göstermemesi dikkati çekmektedir.

\section{Bulgular}

\section{İyon-Dipol Etkileşimleri Kavramının Tanımlarının Analizinden Elde Edilen}

Katılımcılardan, iyon-dipol etkileşimleri kavramının tanımına dair elde edilen bulgular Tablo 7'de sunulmaktadir.

Tablo 7

İyon-Dipol Etkileşimleri Kavramının Tanımları

Fen Bilgisi Öğretmenliğ

Ön Test

$25(\% 49.0)$

$2(\% 3.9)$

$13(\% 25.5)$

$11(\% 21.6)$

Son Test

$36(\% 70.6)$

7 (\%13.7)

$6(\% 11.8)$

$2(\% 3.9)$
Biyoloji Öğretmenliği

$\begin{array}{cc}\text { On Test } & \text { Son Test } \\ 8(\% 38.1) & 15(\% 71.4) \\ 2(\% 9.5) & 3(\% 14.3) \\ 3(\% 14.3) & 2(\% 9.5) \\ 8(\% 38.1) & 1(\% 4.8)\end{array}$

Tablo 7'ye göre çalışmaya katılan bütün öğrencilerin iyon-dipol etkileşimleri kavramıyla ilgili tanımlarının öğretim sonunda öncesine göre geliştiği görülmektedir. 


\section{Metalik Bağ Kavramının Tanımlarının Analizinden Elde Edilen Bulgular}

Metalik Bağ Kavramının tanımı kapsamında araştırmaya katılan öğrencilerden elde edilen bulguların sunumu Tablo 8'de gösterilmektedir.

Tablo 8

Metalik Băg Kavramının Tanımları

\begin{tabular}{lcccc}
\hline & \multicolumn{2}{c}{ Fen Bilgisi Öğretmenliği } & \multicolumn{2}{c}{ Biyoloji Öğretmenliği } \\
\hline Kategoriler & On Test & Son Test & Ön Test & Son Test \\
\hline Tam Doğru & $3(\% 5.9)$ & $26(\% 51.0)$ & - & $6(\% 28.6)$ \\
Kısmen Doğru & $30(\% 58.8)$ & $20(\% 39.2)$ & $10(\% 47.6)$ & $14(\% 66.7)$ \\
Yanlış & $10(\% 19.6)$ & $4(\% 7.8)$ & $1(\% 4.8)$ & $1(\% 4.8)$ \\
Cevapsız & $8(\% 15.7)$ & $1(\% 1.9)$ & $10(\% 47.6)$ & - \\
\hline
\end{tabular}

Tablo 8 dikkate alındığında, metalik bağ kavramıyla ilgili olarak ön testte Biyoloji Öğretmenliği Programı öğrencileri tarafından hiç tam doğru tanım yapılamadığı görülmektedir. Fen Bilgisi Öğretmenliği Programında ön testte öğrencilerin yaklaşık olarak yarısının tam doğru tanım yaptığı bulunmuştur. Öğretim sonucunda ise her iki programda da yapılan tanımların geliştiği ortaya çıkmıştır.

\section{Van der Waals Bağları Kavramının Tanımlarının Analizinden Elde Edilen Bulgular}

Van der Waals Bağları Kavramının tanımıyla ilgili katılımcılardan elde edilen bulgular Tablo 9'da yer almaktadır.

Tablo 9

Van der Waals Bağları Kavramının Tanımları

\begin{tabular}{lcccc}
\hline & \multicolumn{2}{c}{ Fen Bilgisi Öğretmenliği } & \multicolumn{2}{c}{ Biyoloji Öğretmenliği } \\
\hline Kategoriler & $\ddot{O} n$ Test & Son Test & Ön Test & Son Test \\
\hline Tam Doğru & $3(\% 5.9)$ & $14(\% 27.5)$ & - & - \\
Kismen Doğru & $15(\% 29.4)$ & $31(\% 60.8)$ & $5(\% 23.8)$ & $14(\% 66.7)$ \\
Yanlış & $6(\% 11.8)$ & $1(\% 1.9)$ & $1(\% 4.8)$ & $1(\% 4.8)$ \\
Cevapsı) & $27(\% 52.9)$ & $5(\% 9.8)$ & $15(\% 71.4)$ & $6(\% 28.6)$ \\
\hline
\end{tabular}

Tablo 9'a göre Fen Bilgisi Öğretmenliği Programı öğrencilerinin Van der Waals Bağlarıyla ilgili tanımlarının öğretim sonunda öğretim öncesine göre geliştiği bulunmuştur. Biyoloji Öğretmenliği Programı öğrencileri tarafından yapılan tanımlar incelendiğinde ise hem öğretim öncesinde hem de öğretim sonrasında hiç tam doğru cevap elde edilememesi dikkati çekmekte olup diğer kategorilerde öğretime bağlı olarak gelişmeler ortaya çıkmıştır. 
İndüklenmiş Dipol Etkileşimleri Kavramının Tanımlarının Analizinden

\section{Elde Edilen Bulgular}

Çalışmaya katılan öğrencilerden, indüklenmiş dipol etkileşimleri kavramının tanımına dair elde edilen bulgular Tablo 10'da sunulmaktadır.

Tablo 10

İndüklenmiş Dipol Etkileşimleri Kavramının Tanımları

\begin{tabular}{lcccc}
\hline & \multicolumn{2}{c}{ Fen Bilgisi Öğretmenliği } & \multicolumn{2}{c}{ Biyoloji Öğretmenliği } \\
\hline Kategoriler & $\ddot{O}$ Test & Son Test & Ön Test & Son Test \\
\hline Tam Doğru & - & $13(\% 25.5)$ & - & $4(\% 19.0)$ \\
Kismen Doğru & $19(\% 37.3)$ & $23(\% 45.1)$ & $8(\% 38.1)$ & $10(\% 47.6)$ \\
Yanlış & $12(\% 23.5)$ & $11(\% 21.6)$ & $3(\% 14.3)$ & $5(\% 23.8)$ \\
Cevapsız & $20(\% 39.2)$ & $4(\% 7.8)$ & $10(\% 47.6)$ & $2(\% 9.5)$ \\
\hline
\end{tabular}

Tablo 10'a göre indüklenmiş dipol etkileşimleri kavramıyla ilgili ön testte her iki program öğrencileri tarafindan da tam doğru tanım yapılamadığı bulunmuştur. Buna karşı1ık gerçekleştirilen öğretim sonucunda Fen Bilgisi Öğretmenliği Programı öğrencilerden elde edilen tanımların düzeyinin geliştiği; Biyoloji Öğretmenliği'nin ise daha sınırlı bir gelişme gösterdiği görülmektedir.

\section{Sonuç ve Tartışma}

Araştırmadan elde edilen sonuçlar genel olarak değerlendirildiğinde; Sorgulamaya Dayalı Öğrenmenin öğrencilerin verilen kavramları tanımlamaları üzerinde olumlu etkiler gösterdiği söylenebilir. Çalışmanın başlangıcında, öğrencilerin yaptıkları tanımların bilimsel açıdan daha az kabul edilebilir düzeyde olduğu tespit edilmiştir. Gerçekleştirilen çalışma sonucunda ise her iki program öğrencilerinin de ele alınan kavramları tanımlamalarında gelişmeler olduğu görülmektedir. $\mathrm{Bu}$ sonuç, alanyazında Sorgulamaya Dayalı Öğrenme temel alınarak gerçekleştirilmiş araştırmalarda öğrencilerin çeşitli kavramları anlamaları ve başarıları kapsamında alınan olumlu sonuçlar ile benzerlik göstermektedir (Bostan-Sarı̆̆lan \& Abac1, 2017; Kaya \& Yılmaz, 2016; Kayacan \& Selvi, 2017; Şimşek \& Kabapınar, 2010). Araştırmadan elde edilen bu sonuç, çalışmaya katılan öğrencilerin öğrenim gördükleri program açısından ele alındığında ise öğrencilerin yaptıkları tanımlarla ilgili kavramalarının öğrenim gördükleri programa göre değişiklikler gösterdiğini ortaya koymaktadır. Fen Bilgisi Öğretmenliği öğrencilerinin çalışmaya konu olan kavramların tanımlarını, Biyoloji Öğretmenliği öğrencilerine göre zihinlerinde daha doğru yapılandırdıkları söylenebilir. Bunun sebebi, Fen Bilgisi Öğretmenliği öğrencilerinin; kimya konularına daha ilgili olmasından ve Genel Kimya dersinin Fen Bilgisi Öğretmenliği'nin haftalık programında daha fazla ders saatine sahip olmasından kaynaklanabilir. Ayrıca, daha önce öğrencilerin bağlar konusundaki kavramalarının üniversitede öğrenim gördükleri sınıf düzeyine göre farklılaştığı ortaya konulduğu gibi (Yılmaz \& Morgil, 2001) sınıf düzeyi farklılaşsa bile değişime karşı dirençli olan kavram yanılgılarının da bulunduğu belirtilmiştir (Nicoll, 2010). Yani alanyazına göre aynı konunun öğrenilmesi, aynı 
bölümün sınıf düzeyine göre bile farklılık gösterdiği düşünüldüğünde, faklı bölümlerde öğrenim öğrenciler için böyle bir sonucun ortaya çıkması da doğal olarak düşünülebilir.

Çalışmanın başlangıcında da belirtildiği üzere, Sorgulamaya Dayalı Öğretim ile öğrencilerin fen kavramlarını bilimsel açıdan tam doğru bir şekilde anlamalarını sağlamak amaçlanmaktadır. Yapılan çalışmada, her iki programda da son test sonucunda ön teste göre artış elde edilen tam doğru cevaplar, bu bilimsel amacı karşılamaktadır. Tam doğru kategorisinde son test lehine artış belirlenen kavramların tanımlar1; kimyasal bağ, iyonik bağ, dipol-dipol etkileşimi, hidrojen bağ1 ve iyon-dipol etkileşilerine aittir. $\mathrm{Bu}$ sonuç, gerçekleştirilen Sorgulamaya Dayalı Öğrenme ile öğrencilerin bu kavramları zihinlerinde daha iyi bir şekilde yapılandırabildiklerini ortaya koymaktadır. Bu kapsamda, ele alınan kimyasal bağ kavramının araştırmaya temel olduğu düşünüldüğünde; öğrencilerin yaptıkları tanımların iyileşmesi, Uzuntiryaki'nin (2003) çalışması sonucunda hem deney hem de kontrol grubunda kimyasal bağ kavramıyla ilgili elde ettiği doğru cevaplardaki artış ile benzerlik göstermektedir.

Sadece Fen Bilgisi Öğretmenliği öğrencilerinin cevaplarında son test lehine artı̧̧ gözlenen kavramlar; kovalent bağ, metalik bağ ve Van der Waals bağlarının tanımlarına aittir. Buna karşılık Biyoloji Öğretmenliği öğrencilerinin kovalent bağ ile ilgili tanımlarında ön test ve son test arasında bir değişiklik tespit edilmemiştir. Bu sonuç ilgi çekicidir. Öztürk Ürek ve Tarhan (2005) lise birinci sınıf öğrencileri ile gerçekleştirdikleri çalışmanın başlangıcında öğrencilerinin yaklaşık yarısının (\%47) HCl'nin kovalent bağlı olmasına rağmen öğrencilerin iyonik bağlı bir bileşik olduğunu düşündüklerini tespit etmiştir. Bir başka çalışmada da üniversite öğrencilerinin tanım yapabilmelerine rağmen kovalent bağ ile ilgili birçok kavram yanılgısı taşıdıklarına dikkat çekilmiştir (Luxford \& Lowery Bretz, 2013). Yapılan çalışmada kovalent bă̆ konusunda Biyoloji Öğretmenliği Programı öğrencilerinin tanımlarının değişmemesi, tespit edilen bu kavram yanılgılarının yaygınlığı ile ilişkilendirildiğinde olası kabul edilebilir. Ayrıca, bu program öğrencilerinin metalik bağ ve Van der Waals bağları kavramları ile ilgili tanımlarında ön testte tam doğru kategorisine ait herhangi bir cevap bulunmazken gerçekleştirilen öğretim sonucunda yapılan son testte tam doğru cevapların yer aldığı görülmektedir. Alanyazındaki başka bir çalışmada ise lise birinci sınıf öğrencilerinin metalik bağ ile ilgili kavram yanılgılarının olduğu belirlenmiştir (Acar \& Tarhan, 2008). Kovalent bağ kavramında olduğu gibi metalik bağ kavramında da lise seviyesindeki öğrencilerde tespit edilen kavram yanılgılarının bu kavramların üniversite düzeyindeki öğrenmelere engel teşkil ettiği düşünülmektedir.

Biyoloji Öğretmenliği öğrencilerinin gerçekleştirilen öğretime rağmen, ön test sonuçlarında olduğu gibi son test sonuçları da Van der Waals bağlarının tanımlarıyla ilgili tam doğru cevap bulunmadığını göstermektedir. Bu sonuç, Biyoloji Öğretmenliği öğrencilerinin yapılan öğretime rağmen Van der Waals bağları kavramını zihinlerinde tam doğru bir şekilde yapılandıramadıklarını göstermektedir. Tan ve Treagust (1999) lise seviyesindeki öğrenciler ile gerçekleştirdikleri çalışmaları sonucunda, öğrencilerin moleküller arası kuvvetlerle ilgili kavram yanılgısı oranını yaklaşık \%61 olduğunu belirlemiş olup bu kavram yanılgısı, çalışmalarında tespit ettikleri en yaygın ikinci kavram yanılgısı olarak karşımıza çıkmaktadır. Yapılan çalışmada da bir çeşit moleküller arası etkileşim türü olan Van der Waals bağları kavramının, öğretim açısından kimya eğitimcilerinin karşısına zorlayıcı bir kavram olarak çıktığı ve 
eğitimcilerin gerçekleştirdikleri öğretimde bu durumu göz önünde bulundurmaları gerektiği görülmektedir. Animasyon, video, multimedya gibi bu tür kavramları somutlaştırarak görsel açıdan destekleyecek yöntem ve tekniklerin bu kavramların öğretimine yardımcı olacağı düşünülmektedir (Pekdağ, 2010).

Her iki program öğrencilerinin ön test sonuçları arasında tam doğru cevabının bulunmadığg kavram; indüklenmiş dipoldür. Benzer şekilde Uzuntiryaki (2003) tarafından kimyasal bağlar konusunda gerçekleştirilen bir çalışmada da ön test sonucunda deney grubundaki dokuzuncu sınıf öğrencilerinden HF'de bulunan elektron bulutunun dağılımıyla ilgili hiç doğru cevap alınamamıştır. İndüklenmiş dipol tanımıyla ilgili bu sonuç, bu kavramın tanımının önceden büyük oranda bilinmediğini ortaya koymaktadır. Yapılan öğretim sonucunda her iki programın da son test sonuçlarına bakıldığında; tam doğru kategorisinde artış olması ve cevapsız kategorisinin frekansının düşük olması, bu kavramın tanımının büyük oranda öğrenildiği sonucunu ortaya koymaktadir.

Sonuç olarak gerçekleştirilen öğretim sonucunda; Sorgulamaya Dayalı Öğrenmenin üniversite öğrencileri üzerinde olumlu etki gösterdiği ve araştırmaya katılan her iki bölüm öğrencileri için de yapılan öğretim sonucunda kavramları tanımlamalarında gelişmeler olduğu bulunmuştur. Yapılan araştırmanın, Özmen'in (2004) de belirttiği gibi öğretmenlerin bu konuyu öğretmeden önce öğrencilerin hazır bulunuşluğunu göz önünde bulundurmaları açısından ve bu nedenle araştırmalar ile öğretim arasındaki boşluğu doldurması açısından alana katkılarda bulunması beklenmektedir. Yapılan araştırma sonuçlarına dayanarak, bu öğrenme yaklaşımının üniversite öğrencilerinde de farklı konu ve kavramların öğretiminde kullanılması önerilmektedir. 


\section{Summary}

Purpose and Significance: The aim of this study is to investigate the definitions made by university level students related to the concept of chemical interactions as well as identifying the effect of Inquiry Based Learning on their definitions. In this study, it has been accepted that knowledge level provides a threshold for learning of higher-level abilities. Hence, in this paper, this case has been considered in terms of university level students. Also, the study gains importance when the study sample is thought to be future teachers. Thus, the concept of chemical interactions which is one of the difficult and abstract concepts of General Chemistry has been addressed via Inquiry Based Learning at this respect. So, the study is believed to contribute to the literature in terms of its findings and carry significance.

Methods: The study was conducted by means of a qualitative approach. The study sample was comprised of Science Teaching ( $\mathrm{f}=51$ ) and Biology Teaching Program ( $\mathrm{f}=21$ ) students studying their first year in the education faculty of a governmental university located in the west part of Turkey. Data of the study were collected with the help of Chemical Interactions Conception Test which possessed nine open ended questions related to the definitions of several concepts about chemical interactions (chemical bond, ionic bond, dipole-dipole inreactions, covalent bond, hydrogen bond, ion-dipole interactions, metallic bond, Van der Waals interactions and induced dipol interactions) developed by the resechers. Data collection was conducted in the form of pre and post tests and analyzed via content analysis which resulted in four categories such as full correct, partially correct, incorrect and no response. The analysis results were presented in the form of tables demonstrating frequency and percentage distributions by comparing Science Teaching and Biology Teaching Program students.

Results: The results of the study were presented for nine concepts addressed in this paper. First of all, both program students were found to inrease their full correct responses from pre to post test in terms of their definitions related to chemical bond concept. Also, the ratio of incorrect responses and no responses were identified to decrease. Moreover, the same results were determined for the concept of ionic bond. In that case, there was no no response both in pre and post test for both program students. The third concept was dipole-dipole interactions and the results also demonstrated an improvement from pre to post test application for both program students. However, the amount of improvement in the full correct definitions of Biology Teaching Program students stayed in a limited level when compared to Science Teaching Program students. Hydrogen bond was another concept researched in the study and the results showed that both program students' definitions improved from pre to post test similar to the previous results. When the case of covalent bond was considered, the level of definitions obtained from Science Teaching Program students were found to improve whereas no change was obtained from the answers of Biology Teaching Program students. Another concept addressed in this study was ion-dipole interactions and the results indicated an improvement for both program students' definitions. When the case of metallic bond was considered, the findings also showed improvement for both programs from pre to post test. However, no full correct response was obtained from 
Biology Teaching Program students in pre test application whereas there were such answers from Science Teaching Program students. Also, the ratio of incorrect answers did not change for Biology Teaching Program students in the post test. The results of the analysis of the definitions of Van der Waals interactions showed an improvement for Science Teaching Program students whereas Biology Teaching Program students' improvement stayed in a limited level with no full correct responses in both pre and post test applications. Finally, the results obtained from the analysis of induced dipole interactions showed similar improvements in both program students' definitions where no full correct responses were obtained from pre-test application of both program students' answers.

Discussion and Conclusions: To conclude, it can be stated that Inquiry Based Learning made positive effects on students' definitions related to chemical interactions. However, it was seen that the level of the definitions differentiated according to the program of the participants. The level of several definitions obtained from Biology Teaching Program stayed limited. Science Teaching Program students were determined to construct the aforementioned concepts in thier minds better. When the students' responses were examined in the category of full correct, both program students' responses were found to improve in terms of the concepts of chemical bond, ionic bond, dipole-dipole interactions, hydrogen bond and ion-dipole interactions which proved the positive effect of Inquiry Based Learning on students' learning. On the other hand, only Science Teaching Program students' definitions were identified to improve from pre to post test application about the concepts of covalent bond, metallic bond and Van der Waals interactions. Besides, no change was obtained from Biology Teaching Program students related to the concept of covalent bond in addition to no full correct responses related to metallic bond and Van der Waals interactions from pre-test application. Also, the sole concept from which no full correct response was obtained in the pre-test was determined to be inducted dipol intearctions. The results were found to be consistent with the litearture and presents significant findings related to students' learning to be considered by science and chemistry educators. Finally, it can be recommended to utilize technological support such as animation and multimedia to enhance students' learning in addition to Inquiry Based Approach related to the teaching of chemical interactions and bonds. 


\section{Kaynakça}

Abdi, A. (2014). The effect of inquiry-based learning method on students' academic achievement in science course. Universal Journal of Educational Research, 2(1), 37-41. DOI: 10.13189/ujer.2014.020104

Acar, B., \& Tarhan, L. (2008). Effects of cooperative learning on students' understanding of metallic bonding. Research in Science Education, 38(4), 401-420. https://doi.org/10.1007/s11165-007-9054-9

Airasian, P. W., Cruikshank, K. A., Mayer, R. E., Pintrich, P. R., Raths, J., \& Wittrock, M. C. (2001). (Eds. Anderson, L.W. \& D. R. Krathwohl, D. R.). A taxonomy for learning, teaching, and assessing: A revision of Bloom's Taxonomy of Educational Objectives. (Complete edition). New York: Longman.

Ayas, A. (2012). Kavram Öğretimi. İçinde S. Çepni (Ed.) Kuramdan uygulamaya fen ve teknoloji ögrretimi (10. Bask1). (ss.151-177). Ankara: Pegem Akademi Yayınc1lık.

Bayram, Z. (2015). Sorgulamaya Dayalı Kimya Öğretimi Uygulamaları. İçinde A. Ayas \& M. Sözbilir (Eds.). Kimya Öğretimi, öğretmen ĕgitimcileri, öğretmenler ve ögretmen adayları için iyi uygulama örnekleri (ss. 445-461). Ankara: Pegem Akademi Yayıncılık.

Bostan Sarığlan, A., \& Abac1, B. (2017). Sorgulamaya dayalı öğretimin "lamba parlaklığı" kavramının ortaokul 5. sınıf öğrencilerinin başarısına etkisi. Balıkesir Üniversitesi Fen Bilimleri Enstitüsü Dergisi, 9(3) Özel Say1, 164-171. DOI: 10.25092/baunfbed.366220

Büyüköztürk, Ş., Kılıç Çakmak, E., Akgün, Ö. E., Karadeniz, Ş., \& Demirel, F. (2010). Bilimsel araştırma yöntemleri (6. Baskı). Ankara: Pegem Akademi Yayıncılık.

Chang, R. (2000). Fen ve mühendislik bölümleri için kimya. (Çev. Ed. A. B. Soydan \& A. Z. Aroğuz). İstanbul: Beta Basım Dağıtım A. Ş.

Coll, R. K., \& Treagust, D. F. (2003). Investigation of secondary school, undergraduate, and graduate learners' mental models of ionic bonding. Journal of Research in Science Teaching, 40, 464-486. https://doi.org/10.1002/tea.10085

Coll, R. K., \& Taylor, N. (2002). Mental models in chemistry: senior chemistry students $\square$ mental models of chemical bonding. Chemistry Education Research and Practice, 3, 175-184. DOI: 10.1039/B2RP90014A

Çelik, S., Şenocak, E., Bayrakçeken, S., Taşkesenligil, Y., \& Doymuş, K. (2005). Aktif öğrenme stratejisi üzerine bir derleme çalışması. Kazım Karabekir Eğitim Fakültesi Dergisi, 11, 155-185.

Dolu, G. (2017). Kimyasal Bağlar. İçinde H. Bağ (Ed.) Genel kimya I (8. Baskı) (ss.137-163). Ankara: Pegem Akademi Yayıncılık.

Dolu, G., \& Ürek, H. (2018, Mayıs). Sivılar konusunun öğrencilerin ürettikleri sloganlar yardımıyla değerlendirilmesi. VIII. Uluslararası Eğitimde Araştırmalar Kongresi'nde sunulmuş sözlü bildiri, Manisa, Türkiye.

Duru, M. K., Demir, S, Önen, F., \& Benzer, E. (2011). Sorgulamaya dayalı laboratuvar uygulamalarının öğretmen adaylarının laboratuvar algısına tutumuna ve bilimsel 
süreç becerilerine etkisi. M.Ü. Atatürk Ĕ̆itim Fakültesi Eğitim Bilimleri Dergisi, $33,25-44$.

Edelson, D. C., Gordin, D. N., \& Pea, R. D. (1999). Addressing the challenges of inquiry-based learning through technology and curriculum design. Journal of the Learning Sciences, 8(3-4), 391-450. DOI: 10.1080/10508406.1999.9672075

Gormally, C., Brickman, P., Hallar, B., \& Armstrong, N. (2009). Effects of inquirybased learning on students' science literacy skills and confidence. International Journal for the Scholarship of Teaching and Learning, 3(2), 1-22. DOI: https://doi.org/10.20429/ijsotl.2009.030216

Karamustafaoğlu, S., \& Celep Havuz, A. (2016). Inquiry based learning and its effectiveness. International Journal of Assessment Tools in Education, 3(1), 40-54.

Kaya, G., \& Yılmaz, S. (2016). Açık sorgulamaya dayalı öğrenmenin öğrencilerin başarısına ve bilimsel süreç becerilerinin gelişimine etkisi. Hacettepe Üniversitesi Eğitim Fakültesi Dergisi, 31(2), 300-318. DOI:10.16986/HUJE.2016016811

Kayacan, K., \& Selvi, M. (2017). Öz düzenleme faaliyetleri ile zenginleştirilmiş araştırma-sorgulamaya dayalı öğretim stratejisinin kavramsal anlamaya ve akademik öz yeterliğe etkisi. Kastamonu Ĕ̈itim Dergisi, 25(5), 1771-1786.

Krathwohl, D. R. (2002). A Revision of bloom's taxonomy: an overview. Theory into practice, 41(4), 212-218. DOI: 10.1207/s15430421tip4104_2

Kocagül, M. (2013). Sorgulamaya dayalı mesleki gelişim etkinliklerinin ilköğretim fen ve teknoloji öğretmenlerinin bilimsel süreç becerilerine, öz-yeterlik ve sorgulamaya dayalı öğretime ilişkin inançlarına etkisi (Yayımlanmamış yüksek lisans tezi). Dokuz Eylül Üniversitesi, İzmir.

Küçük, M., Çepni, S., \& Tavşan, O. (2004, Temmuz). Fen bilgisi öğretmen adaylarının eğitimle ilgili bazı kavramları anlama seviyeleri. XIII. Ulusal Eğitim Bilimleri Kurultayı, İnönü Üniversitesi, Eğitim Fakültesi, Malatya.

Levy, P., \& Petrulis, R. (2012). How do first-year university students experience inquiry and research, and what are the implications for the practice of inquiry-based learning?. Studies in Higher Education, 37(1), 85-101. DOI: 10.1080/03075079.2010.499166

Luxford, C. J., \& Lowery Bretz, S. (2013). Moving beyond definitions: what studentgenerated models reveal about their understanding of covalent bonding and ionic bonding. Chemistry Education Research and Practice, 14, 214-222. DOI: 10.1039/C3RP20154F

Magnussen, L., Ishida, D., \& Itano, J. (2000). The impact of the use of inquiry-based learning as a teaching methodology on the development of critical thinking. Journal of Nursing Education, 39(8), 360-364. https://doi.org/10.3928/0148-483420001101-07

McMillan, J. H. (2004). Educational research: fundamentals for the consumer. (4th Ed.), Boston: Allyn and Bacon.

Miles, M. B., \& Huberman, A. M. (1994). Qualitative data analysis an expanded sourcebook. ( $2^{\text {nd }}$ Ed.), California: Sage Publications.

Nicoll, G. (2010). A report of undergraduates' bonding misconceptions. International Journal of Science Education, 23(7), 707-730. DOI: 10.1080/09500690010025012 
Oliver, R. (2007). Exploring an inquiry-based learning approach with first-year students in a large undergraduate class. Innovations in Education and Teaching International, 44(1), 3-15. DOI: 10.1080/14703290601090317

Öztürk Ürek, R., \& Tarhan, L. (2005). “Kovalent bağlar” konusundaki kavram yanılgılarının giderilmesinde yapılandırmacılığa dayalı bir aktif ögrenme uygulamas1. Hacettepe Üniversitesi Ĕ̆itim Fakültesi Dergisi, 28, 168-177.

Özmen, H. (2004). Some student misconceptions in chemistry: a literature review of chemical bonding. Journal of Science Education and Technology, 13(2), 147-159.

Petrucci, R. H., Herring, F. G., Madura, J. D., \& Bissonnette, C. (2012). Genel kimya, ilkeler ve modern uygulamalar (Çev. Ed. Uyar, T. \& Aksoy, S. \& İnam, R.). Ankara: Palme Yayıncılık. (Özgün çalışma, 2011).

Pekdağ, B. (2010). Kimya öğreniminde alternatif yollar: animasyon, simülasyon, video ve multimedya ile Öğrenme. Türk Fen Eğitimi Dergisi, 7(2), 79-110.

Raymond, C. (2000). Kimya, fen ve mühendislik bölümleri için. (Çev. Ed. Soydan, A. B. \& Aroğuz, A. Z.). İstanbul: Beta Yayıncılık. (Özgün çalışma, 1998).

Sarı, U., \& Bakır Güven, G. (2013). Etkileşimli tahta destekli sorgulamaya dayalı fizik öğretiminin başarı ve motivasyona etkisi ve öğretmen adaylarının öğretime yönelik görüşleri. Necatibey Ĕgitim Fakültesi Elektronik Fen ve Matematik Eğitimi Dergisi, 7(2), 110-143.

Senemoğlu, N. (2009). Gelişim, ögrrenme ve ögrretim, kuramdan uygulamaya. Ankara: Pegem Akademi.

Spronken-Smith, R., \& Walker, R. (2010). Can inquiry-based learning strengthen the links between teaching and disciplinary research?. Studies in Higher Education, 35(6), 723-740. DOI: 10.1080/03075070903315502

Şimşek, P., \& Kabapınar, F. (2010). The effects of inquiry-based learning on elementary students' conceptual understanding of matter, scientific process skills and science attitudes. Procedia Social and Behavioral Sciences, 2, 1190-1194. DOI:10.1016/j.sbspro.2010.03.170

Tan, D. K. - C., \& Treagust, D. F. (1999). Evaluating students' understanding of chemical bonding. School Science Review, 81(294), 75-84.

Uzuntiryaki, E. (2003). Effectiveness of constructivist approach on students' understanding of chemical bonding concepts (Yayımlanmamıs doktora tezi). Orta Doğu Teknik Üniversitesi, Ankara.

Wu, H.-K., \& Hsieh, C.-E. (2006). Developing sixth graders' inquiry skills to construct explanations in inquiry-based learning environments. International Journal of Science Education, 28(11), 1289-1313. DOI: 10.1080/09500690600621035

Yıldırım, A., \& Şimşek, H. (2008). Sosyal bilimlerde nitel araştırma yöntemleri (6. Bask1). Ankara: Seçkin Yayıncılık.

Y1lmaz, A., \& Morgil, İ. (2001). Üniversite öğrencilerinin kimyasal bağlar konusundaki kavram yanılgılarının belirlenmesi. Hacettepe Üniversitesi Eğitim Fakültesi Dergisi, 20, 172-178. 
YÖK.(1981).Yüksek

öğretim

kanunu.

http://mevzuat.basbakanlik.gov.tr/Metin.Aspx?MevzuatKod=1.5.2547\&MevzuatIli ski=0\&sourceXmlSearch= isimli siteden 20 Mayıs 2018 tarihinde erişilmiştir.

This is an Open Access article distributed under the terms of the Creative CommonsAttributionNonCommercial-ShareAlike 4.0 International (CC BY-NC-SA 4.0). For further information, you can refer to https://creativecommons.org/licenses/by-nc-sa/4.0/ 